\section{A New Kit for Sodium Nitrite-thiosulphate Therapy in the Treatment of Acute Cyanide Poisoning}

\section{N. LANGDON LLOYD}

From the Ministry of Supply

When the sodium nitrite-thiosulphate treatment of acute cyanide poisoning was first adopted in this country, it was difficult to find appropriate equipment (Lloyd Potter, 1950). All-glass $50 \mathrm{ml}$. syringes were unobtainable and it was necessary to manage with the equipment available. This entailed an unavoidable delay in administration of the drugs. Sterilization of the glass components presented difficulty in remote out-stations, where there was the added risk of breakages in transit. Moreover, the condition of the contents of the sealed, sterilized tin was always uncertain.

These outfits have now been replaced in Ministry of Supply establishments by a cyanide emergency kit for medical officers' use, fitted throughout with the "ampin" method of injection. Each kit contains treatment for two persons, with full instructions on an enclosed sheet.

\section{Contents}

For each of two casualties the following is provided:-

Ampin 1 (red label) containing $15 \mathrm{ml} .3 \%$ sodium nitrite in sterile distilled water (the dose, $10 \mathrm{ml}$.).

Ampin 2 (green label) containing $55 \mathrm{ml} .50 \%$ sodium thiosulphate in sterile distilled water (the dose, $50 \mathrm{ml}$.). Five millilitres is allowed in each for tubing space.

Nikethamide, $3 \mathrm{ml}$. for intravenous injection.

Lobeline hydrochloride, $0.003 \mathrm{~g}$. in $1 \mathrm{ml}$. for intramuscular injection.

Nikethamide, $3 \mathrm{ml}$. for intracardiac injection.

Nikethamide and lobeline are supplied in " ampins", which do not need syringes. In the photograph it is a little difficult to appreciate that the containers are " ampins" and not ampoules.

In a compartment are 12 capsules of amyl nitrite, one bottle of surgical spirit, two lengths of rubber tubing for venous tourniquet, one pair of Spencer Wells artery forceps. Sterilized cotton wool and adhesive dressings are added at the establishment and renewed as necessary.

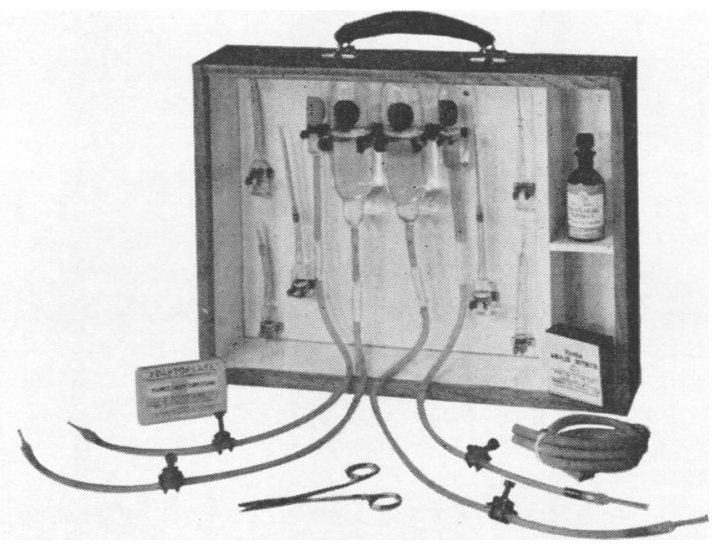

\section{Advantages}

The kit is ready for instant use. Ampins 1 and 2 need not be removed from the case since each is provided with its own length of plastic tubing, drip chamber, and flow control, and both are sterile units in themselves.

Compared with the unpacking and assembly of syringes which must be filled repeatedly, and the technique of injecting at a fixed rate with a large syringe, much time and trouble are saved.

\section{Replacements}

The "ampins" of sodium thiosulphate are replaced once a year, the other " ampins" every third year.

The arrangement is that in any establishment carrying a cyanide hazard, one of these kits is kept at hand in the medical department and one at each site of a cyanide hazard. Following emergency treatment, the spare kit can, if necessary, be sent to hospital with the casualty.

The kit is neatly assembled, clipped into a stout wooden box with a perspex front, standing $15 \frac{1}{2}$ in. wide, 12 in. high, 4 in. deep. It has been made to our requirements by Messrs. Cuxson Gerrard \& Co., Ltd., in consultation with Messrs. Ampins, Ltd., to both of whom we are much indebted for helpful advice.

This kit does not replace the cyanide poisoning firstaid requirements for factories (Factory Form 385Cyanide Poisoning, June 1953) under which amyl nitrite capsules and draughts of cyanide antidote must be held independently at the site of hazard.

\section{REFERENCES} Potter, A. Lloyd (1950). British Journal of Industrial Medicine, 